\title{
Enraizamento de estacas de flor de jade (Strongylodon macrobotrys A. Gray) tratadas com ácido indolbutírico(1)
}

\author{
FABIANA REZENDE MUNIZ(2)* PAULO HERCÍLIO VIEGAS RODRIGUES ${ }^{(2)}$ \\ e SIMONE RODRIGUES DA SILVA ${ }^{(2)}$
}

\begin{abstract}
RESUMO
A flor de jade é uma trepadeira da espécie Strongylodon macrobotrys A. Gray, nativa das Filipinas. Possui inflorescência pseudoracemosa de coloração azul esverdeada, o que a torna única e incomparável. É considerada uma das trepadeiras mais admiradas e procuradas, apesar de rara nos jardins. Este trabalho objetivou avaliar o efeito da aplicação de ácido indolbutírico (AIB) no enraizamento de estacas dessa espécie ornamental. Estacas herbáceas sem folhas e com um par de folhas cortadas ao meio, foram coletadas de ramos de uma planta adulta e bem desenvolvida de flor de jade e submetidas à imersão em solução com AIB ( 0 ; 500; $1.000 ; 2.000 \mathrm{ou} 4000 \mathrm{mg} . \mathrm{L}^{-1}$ ), durante 15 segundos. Posteriormente, a base dessas estacas foi enterrada em bandejas de poliestireno expandido, contendo vermiculita média (uma estaca por célula) e mantidas em câmara de nebulização intermitente por um período de 80 dias quando foram avaliadas quanto a porcentagem de enraizamento, número de raízes e comprimento da maior raiz. Para a produção de mudas de flor de jade deve-se utilizar estacas herbáceas com folhas, tratadas com a concentração de $2.000 \mathrm{mg} \mathrm{L}^{-1} \mathrm{de}$ AIB.

Palavras-chave: propagação, vermiculita, AIB, número de raízes.
\end{abstract}

\section{ABSTRACT}

Rooting of jade vine (Strongylodon macrobotrys A. Gray) cuttings treated with indolbutiric acid

The jade vine (Strongylodon macrobotrys A. Gray), is native plant from Philippines. It has long blue-green pseudoracemes inflorescence, which makes it unique and incomparable. It is considered one of the most admired and sought vines, although rare in gardens. This study evaluated the effect of indolbutiric acid (IBA) on the stalks rooting of this ornamental specie. Stem cuttings without leaves and with a couple of leaves cut in half, were collected from branches of a well developed jade vine plant and were immerged into dipping solutions with a concentration range of IBA $\left(0,500,1.000,2.000\right.$ and $\left.4.000 \mathrm{mg} \mathrm{L}^{-1}\right)$ for 15 seconds. Subsequently, the bases of the cuttings was planted in polystyrene trays containing vermiculite (one cutting per cell) and maintained in an intermittent water mist chamber for a 80 days period. Then the percentage of stem rooting was assessed as well as the number of roots and the length of the main root. Jade vine plants can be produced byr stem cutting treated in a dipping solution containing an IBA concentration of $2.000 \mathrm{mg} \mathrm{L}^{-1}$.

Keywords: propagation, vermiculite, IBA, number of roots.

\section{INTRODUÇÃO}

A flor de jade (Strongylodon macrobotrys A. Gray) é uma planta ornamental perene, trepadeira, vigorosa, da família Fabaceae. Originária das florestas tropicais das Filipinas, essa espécie possui crescimento vigoroso e porte médio de 6 a 8 metros, podendo alcançar até 20 metros de comprimento em condições especiais (TAKEDA et al., 2010).

A planta desenvolve-se muito bem em locais de clima quente e úmido. No Brasil, floresce na primavera/verão e deve ser cultivada a pleno sol ou meia-sombra em solo fértil e enriquecido com matéria orgânica, irrigado a intervalos regulares. Suas flores surgem nos cachos florais que a planta emite no período que vai do fim do inverno ao início da primavera, sendo muito apreciada em função da coloração, que é uma mistura de azul e verde, semelhante à de uma pedra preciosa chamada jade, o que lhe resultou o nome (TAKEDA et al., 2010).
O aumento da demanda por plantas ornamentais tem intensificado a procura por plantas exóticas de grande valor ornamental, o que de acordo com Junqueira e Petz (2008), tem favorecido a diversificação desse mercado. Apesar de exuberante, essa planta é pouco usada em projetos paisagísticos, principalmente pela dificuldade existente na sua propagação, o que eleva o seu valor comercial significativamente.

A escassez de estudos e resultados sobre a propagação vegetativa de jade incentivou a realização desse trabalho, que objetivou avaliar o efeito da aplicação de ácido indolbutírico (AIB) no enraizamento de estacas herbáceas dessa espécie.

\section{MATERIAL E MÉTODOS}

O experimento foi conduzido nas dependências do Departamento de Produção Vegetal da ESALQ/USP, em Piracicaba-SP. De uma planta adulta de flor de jade, mantida

\footnotetext{
(1) Recebido em 09/03/2013 e aceito em 17/11/2015.

(2) Universidade de São Paulo (USP), Escola Superior de Agricultura “Luiz de Queiroz", 13418-900, Piracicaba-SP, Brasil. *Autor correspondente: fabiana.muniz@hotmail.com.br
} 
como planta matriz e conduzida sob o sistema latada, foram coletadas estacas herbáceas da porção mediana dos ramos, no mês de setembro de 2013, padronizadas com aproximadamente $0,6 \mathrm{~cm}$ de diâmetro e duas gemas. $\mathrm{O}$ conjunto de estacas foi dividido em estacas com folhas e sem folhas. As estacas com folhas apresentaram apenas um par de folhas com metade do limbo foliar. A base dessas estacas foi tratada com AIB nas concentrações de 0, 500, $1.000,2.000$ e $4.000 \mathrm{mg} . \mathrm{L}^{-1}$ por imersão rápida de 15 segundos. Em seguida, as estacas foram acondicionadas em células de bandejas de poliestireno expandido, contendo vermiculita de textura média da empresa Eucatex, unidade localizada em Paulínia, SP, como substrato. As bandejas foram mantidas por 80 dias em câmara de nebulização intermitente (temperatura de $25 \pm 5{ }^{\circ} \mathrm{C}$, UR média de $72 \%$, tempo de aspersão de 20 segundos, em intervalos de 10 minutos), para indução do enraizamento das estacas.

O delineamento experimental adotado foi o inteiramente casualizado em esquema fatorial $5 \times 2$, representado pelas concentrações de AIB e estacas (sem folhas e com folhas). Cada tratamento foi constituído por quatro repetições de seis plantas. Após 80 dias, foram avaliadas as variáveis: porcentagem de estacas enraizadas, número de raízes por estaca e o comprimento da maior raiz. Os dados foram submetidos à análise de variância (teste F), as médias pelo teste de Tukey a 5\% (SILVA e AZEVEDO, 2002) e regressão polinomial por meio do software Sistema para Análise de Variância - SISVAR (FERREIRA, 2011).

\section{RESULTADOS E DISCUSSÃO}

Estacas de flor de jade com folhas apresentaram maior porcentagem de enraizamento que as estacas sem folhas em todas as concentrações de AIB avaliadas (Tabela 1), sendo as principais diferenças observadas nas concentrações de $0,2.000$ e $4.000 \mathrm{mg} \mathrm{L}^{-1}$, em que as estacas com folhas apresentaram porcentagem de enraizamento similar e significativamente superior aos demais tratamentos, de $41,66 \%$, enquanto as estacas sem folhas apresentaram o maior valor para esta variável, de $29,16 \%$, na concentração de $500 \mathrm{mg} \mathrm{L}^{-1}$ e nenhum enraizamento na concentração de $4.000 \mathrm{mg} \mathrm{L}^{-1}$ de AIB (Figura 1).

Tabela 1. Porcentagem de enraizamento de estacas de flor de jade, com e sem folhas, em diferentes concentrações de AIB. Table 1. Percentage of rooting of cuttings of stem jade wine, with or without leaves, in different concentrations of IBA.

\begin{tabular}{|c|c|c|c|c|c|}
\hline \multicolumn{7}{|c|}{ Concentração de AIB (mg L-1) * } \\
\hline Estacas & 0 & 500 & 1000 & 2000 & 4000 \\
\hline Com Folhas & $41,66 \mathrm{aA}$ & $33,33 \mathrm{aA}$ & $29,17 \mathrm{aA}$ & $41,66 \mathrm{aA}$ & $41,66 \mathrm{aA}$ \\
\hline Sem Folhas & $4,16 \mathrm{bB}$ & $29,16 \mathrm{aA}$ & $8,33 \mathrm{bB}$ & $12,49 \mathrm{bB}$ & $0,00 \mathrm{bB}$ \\
\hline
\end{tabular}

*As médias seguidas pela mesma letra não diferem estatisticamente entre si pelo Teste de Tukey ao nível de 5\% de probabilidade.

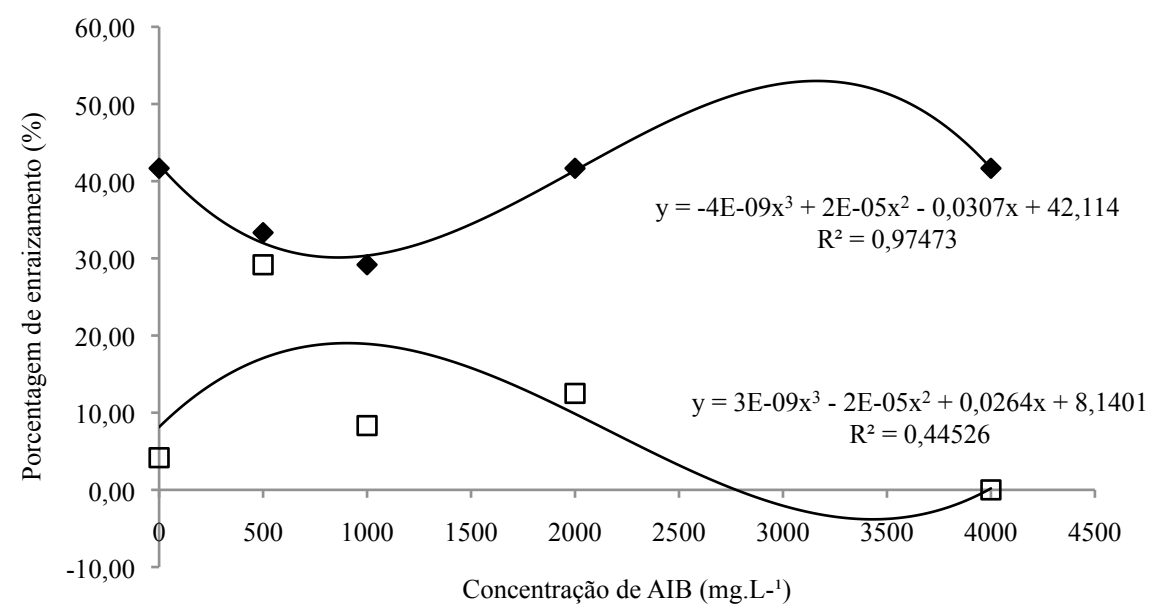

Difere significativamente $(\mathrm{P}<0,05) / \quad=$ estaca com folha $/ \quad=$ estaca sem folha

Figura 1. Porcentagem de enraizamento de estacas herbáceas de flor de jade (Strongylodon macrobotrys A. Gray) com e sem folhas, tratadas com diferentes concentrações de ácido indolbutírico.

Figure 1. Rooting of cuttings of stem jade wine (Strongylodon macrobotrys A. Gray) with or without leaves, treated with different concentrations of indolbutiric acid. 
Gratieri-Sossella et al. (2008) não verificaram diferenças significativas na porcentagem de enraizamento de miniestacas herbáceas de corticeira-do-banhado (Erythrina crista-galli L.), também da família Fabaceae e de uso ornamental, nas concentrações de 0, 1.000, 2.000, 3.000 e $4.000 \mathrm{mg} \mathrm{L}^{-1}$, cujos valores variaram de 75 a $100 \%$, resultados superiores aos obtidos neste trabalho para estacas de flor de jade com folhas. Por outro lado, Santos et al. (2014) não observaram formação de raízes em estacas herbáceas de mulungu (Erythrina velutina Willd), espécie arbórea também da família Fabaceae, sob condições de telado e irrigação por microaspersão, ambiente diferente do utilizado para as estacas herbáceas de flor de jade, atribuindo esse resultado a consistência tenra das estacas, que apresenta o inconveniente de apresentar baixa resistência à desidratação. $\mathrm{O}$ processo de enraizamento está relacionado a vários fatores. A presença de folhas nas estacas de jade, pode ter contribuído para o aumento da mobilização de fotoassimilados, favorecendo assim a formação de raízes, já que a síntese dos mesmos envolve a manutenção da atividade metabólica, disponibilizando energia e carbono para o desenvolvimento das raízes (LIONAKIS, 1984).

$\mathrm{O}$ maior número médio de raízes foi observado nas estacas de flor de jade com folhas que nas estacas sem folhas, com as principais diferenças sendo observadas nas concentrações de 1.000 e $2.000 \mathrm{mg} \mathrm{L}^{-1}$ (Figura 2).
Esses resultados confirmam que as folhas, além de serem responsáveis pela produção de fotoassimilados, são locais de síntese de auxina, favorecendo a sobrevivência e formação radicular, enquanto a ausência de folhas pode ter inibido a formação de um número maior de raízes nesses tratamentos (MAYER e PEREIRA, 2003). Neves et al. (2006) não observaram diferenças significativas para o número de raízes em estacas herbáceas de corticeira-daserra (Erythrina falcata Benth), espécie arbórea, também da família Fabaceae entre as doses de 0, 1.500 e 3.000 mg $\mathrm{L}^{-1}$, obtendo resultados de 0,$8 ; 1,6$ e 1,3 número de raízes, respectivamente, valores menores que os observados neste trabalho para estacas de flor de jade com folhas.

Santos et al. (2014) estudando a influência de diferentes concentrações de AIB, épocas de coleta e tipos de estacas no enraizamento de mulungu (E. velutina Willd - Fabaceae) só verificaram resultados eficientes para a variável número de raízes em estacas semilenhosas tratadas com concentrações crescentes de AIB, de 0 a $6.000 \mathrm{mg} \mathrm{L}^{-1}$ e nenhuma formação de raízes em estacas herbáceas, sendo este último resultado diferente do observado para estacas de flor de jade com e sem folhas, respectivamente. Outros fatores podem influenciar a capacidade da estaca em emitir raízes como as condições ambientais na época de coleta das estacas (LEANDRO e YUYAMA, 2008), potencial genético de enraizamento e condições fisiológicas da planta matriz (FACHINELLO et al., 2005).

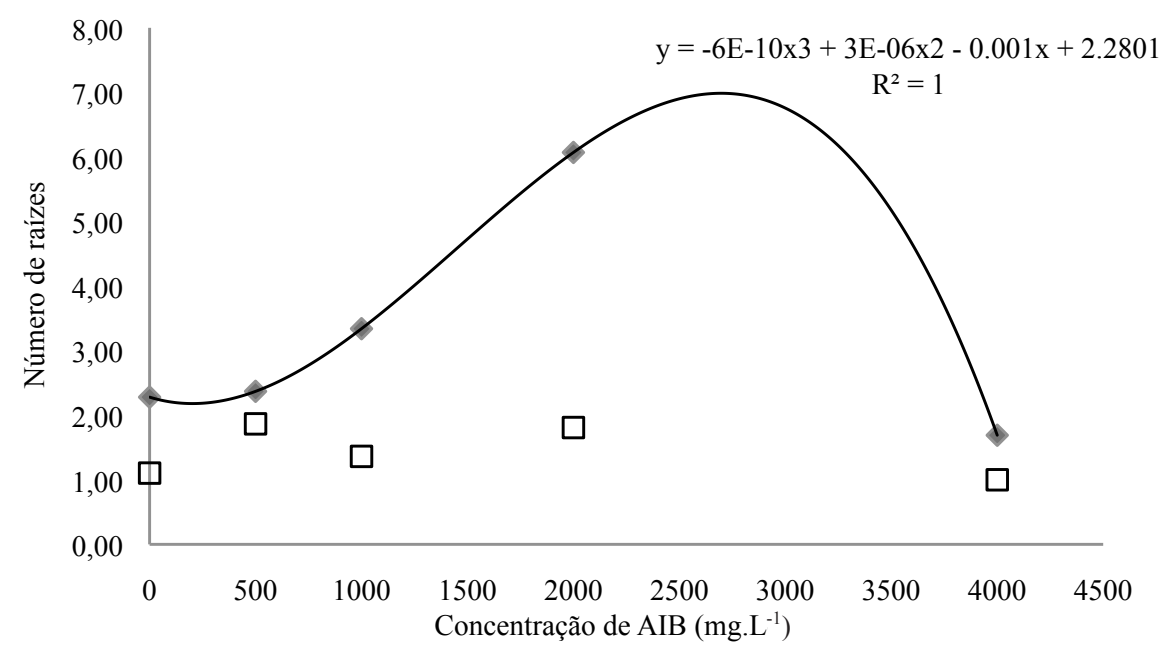

Difere significativamente $(\mathrm{P}<0,05) / \quad=$ estaca com folha $/ \quad=$ estaca sem folha

Figura 2. Número de raízes em estacas herbáceas de flor de jade (Strongylodon macrobotrys A. Gray) com e sem folhas, tratadas com diferentes concentrações de ácido indolbutírico.

Figure 2. Number of roots of stem cuttings jade wine (Strongylodon macrobotrys A. Gray) with or without leaves, treated with different concentrations of indolbutiric acid. 
Também foi observado diferença significativa entre os tipos de estacas, com destaque para a superioridade das estacas com folhas em relação as sem folhas para a variável comprimento da maior raiz em todas as concentrações utilizadas. Nas estacas sem folhas, o comprimento da maior raiz foi estatisticamente igual para todas as concentrações de AIB, enquanto para as estacas com folhas, observou-se uma tendência de aumento no comprimento da raiz até a concentração de $2.000 \mathrm{mg} \mathrm{L}^{-1}$ de AIB, a partir da qual decresceu em grande escala (Figura 3). A aplicação de auxina exógena em estacas pode favorecer o enraizamento, porém altas concentrações podem inibir a formação das mesmas, sendo o teor adequado deste fitorregulador dependente da espécie e da concentração endógena de AIB nos tecidos (FACHINELLO et al., 2005).

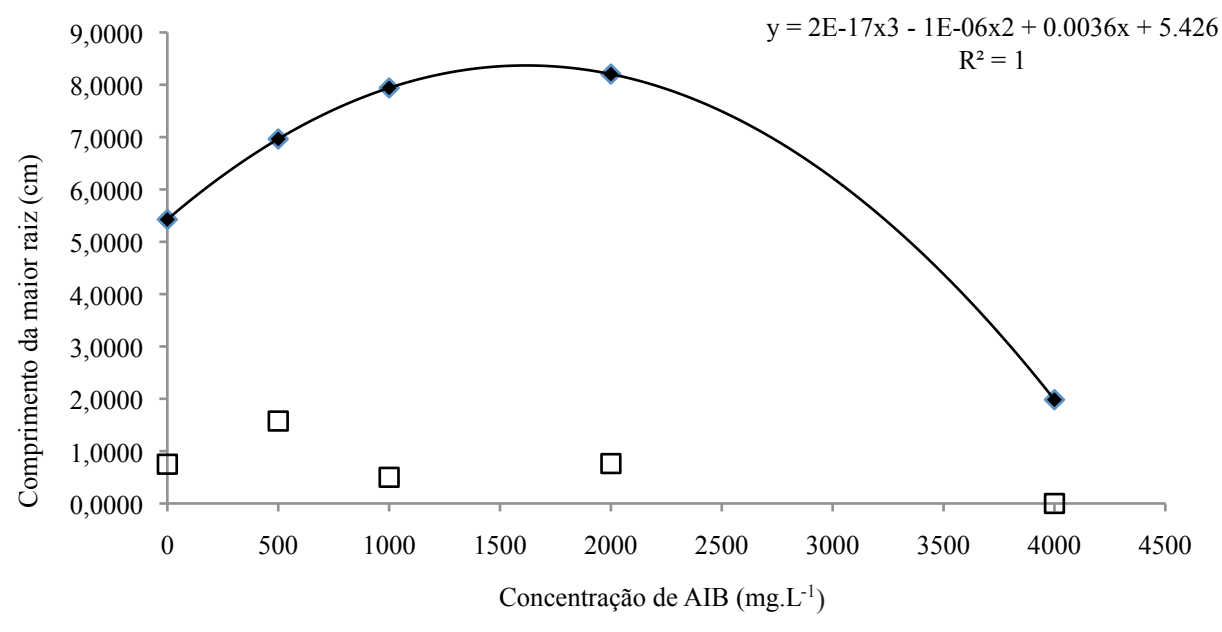

Difere significativamente $(\mathrm{P}<0,05) / \quad=$ estaca com folha / = estaca sem folha

Figura 3. Comprimento da maior raiz em estacas herbáceas de flor de jade (Strongylodon macrobotrys A. Gray) com e sem folhas, tratadas com diferentes concentrações de ácido indolbutírico.

Figure 3. Length of the main root of stem cuttings jade wine (Strongylodon macrobotrys A. Gray) with or without leaves, treated with different concentrations of indolbutiric acid.

\section{CONCLUSÃo}

Para a produção de mudas de flor de jade deve-se utilizar estacas herbáceas com folhas, tratadas com a concentração de $2.000 \mathrm{mg} \mathrm{L}^{-1}$ de AIB.

\section{REFERÊNCIAS}

FACHINELLO, J.C.; HOFFFMANN, A.; NACHTIGAL, J.C. Propagação de plantas frutíferas. Brasília: Embrapa Informação Tecnológica, 2005. 221 p.

FERREIRA, D.F. SISVAR: a computer statistical analysis system. Ciência e Agrotecnologia, Lavras, v.35, n.6, p.1039-1042, 2011.

GRATIERI-SOSSELLA, A.; PETRY, C.; NIENOW, A.A. Propagação da Corticeira do Banhado (Erythrina cristagalli L.) (Fabaceae) pelo processo de estaquia. Revista Árvore, Viçosa, v.32, n.1, p.163-171, 2008.

JUNQUEIRA, H.A.; PEETZ, M.S. Mercado interno para os produtos da floricultura brasileira: características, tendências e importância socioeconômica recente. Revista
Brasileira de Horticultura Ornamental, Campinas, v.14, n.1, p.37-52, 2008.

LEANDRO, R.C.; YUYAMA, K. Enraizamento de estacas de castanha-de-cutia com uso de ácido indolbutírico. Acta Amazônica, Manaus, v.38, n.4, p.597-602, 2008.

LIONAKIS, S.M. Anatomy of root initiation in stem cuttings of Kiwifruit plant (Actinidia chinensis P.). Fruits, Cirad, v.39, p.207-210, 1984.

MAYER, N.A.; PEREIRA, F.M. Enraizamento de estacas herbáceas de quatro clones de umezeiro (Prunus mume Sieb. et Zucc.) durante o inverno ameno, em JaboticabalSP. Revista Brasileira de Fruticultura, Jaboticabal, v.25, n.3, p.505-507, 2003.

NEVES, T.S.; CARPANEZZI, A.A.; ZUFFELLATORIBAS, K.C.; MARENCO, R.A. Enraizamento de corticeira-da-serra em função do tipo de estaca e variações sazonais. Pesquisa Agropecuária Brasileira, Brasília, v.41, n.12, p.1699-1705, 2006.

SANTOS, L.W.; COELHO, M.F.B.; DOMBROSKI, J.L.D.; AZEVEDO, R.A. B. Propagação vegetativa de 
mulungu (Erythrina velutina Willd. - Fabaceae). Revista Brasileira de Ciências Agrárias, Recife, v.9, n.3, p.420426, 2014.

SILVA, F.A.S.; AZEVEDO, C.A.V. Versão do programa computacional Assistat para o sistema operacional Windows. Revista Brasileira de Produtos Agroindustriais, Campina Grande, v.4, n.1, p.71-78, 2002.

TAKEDA, K.; FUJII, A.; SENDA, Y.; IWASHINA, T. Greenish blue flower colour of Strongylodon macrobotrys. Biochemical Systematics and Ecology, Oxford, v.38, n.4, p.1-4, 2010. 